\title{
Administration of a selective retinoic acid receptor- $\gamma$ agonist improves neuromuscular strength in a rodent model of volumetric muscle loss
}

\author{
Michael E. Whitely ${ }^{1 *}$ (D), Patrick B. Collins ${ }^{1}$, Masahiro Iwamoto ${ }^{2}$ and Joseph C. Wenke
}

\begin{abstract}
Purpose: Volumetric muscle loss is a uniquely challenging pathology that results in irrecoverable functional deficits. Furthermore, a breakthrough drug or bioactive factor has yet to be established that adequately improves repair of these severe skeletal muscle injuries. This study sought to assess the ability of an orally administered selective retinoic acid receptor- $\gamma$ agonist, palovarotene, to improve recovery of neuromuscular strength in a rat model of volumetric muscle loss.

Methods: An irrecoverable, full thickness defect was created in the tibialis anterior muscle of Lewis rats and animals were survived for 4 weeks. Functional recovery of the tibialis anterior muscle was assessed in vivo via neural stimulation and determination of peak isometric torque. Histological staining was performed to qualitatively assess fibrous scarring of the defect site.

Results: Treatment with the selective retinoic acid receptor- $y$ agonist, palovarotene, resulted in a 38\% improvement of peak isometric torque in volumetric muscle loss affected limbs after 4 weeks of healing compared to untreated controls. Additionally, preliminary histological assessment suggests that oral administration of palovarotene reduced fibrous scarring at the defect site.

Conclusions: These results highlight the potential role of selective retinoic acid receptor- $\gamma$ agonists in the design of regenerative medicine platforms to maximize skeletal muscle healing. Additional studies are needed to further elucidate cellular responses, optimize therapeutic delivery, and characterize synergistic potential with adjunct therapies.
\end{abstract}

Keywords: Volumetric muscle loss, Muscle function, Palovarotene, RAR agonist

\footnotetext{
* Correspondence: michael.e.whitely2.ctr@mail.mil

'Orthopaedic Trauma Department, United States Army Institute of Surgical Research, 3698 Chambers Pass, Building 3611, JBSA Fort Sam Houston, San Antonio, TX 78234, USA

Full list of author information is available at the end of the article
}

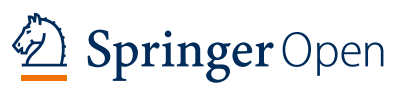

(c) The Author(s). 2021 Open Access This article is licensed under a Creative Commons Attribution 4.0 International License which permits use, sharing, adaptation, distribution and reproduction in any medium or format, as long as you give appropriate credit to the original author(s) and the source, provide a link to the Creative Commons licence, and indicate if changes were made. The images or other third party material in this article are included in the article's Creative Commons licence, unless indicated otherwise in a credit line to the material. If material is not included in the article's Creative Commons licence and your intended use is not permitted by statutory regulation or exceeds the permitted use, you will need to obtain permission directly from the copyright holder. To view a copy of this licence, visit http://creativecommons.org/licenses/by/4.0/. 


\section{Introduction}

Skeletal muscle possesses a robust capacity to recover from injury, stemming from a population of resident progenitor cells who ultimately activate and fuse to repair damaged myofibers $[10,24,50]$. In cases of volumetric muscle loss (VML), however, wherein extensive portions of muscle tissue are lost, this healing cycle breaks down. The loss of progenitor cells and native extracellular matrix combine with an unrelenting immune response that promotes formation of nonfunctional fibrous tissue and severely inhibits de novo fiber regeneration [22, 32, 33]. To date, the clinical standard of care remains surgical placement of muscle flaps followed by extensive rehabilitation [8]. Promising experimental platforms, such as minced muscle graft transplantation, improve muscle function and fiber regeneration, but have been unable to fully mitigate the pathological response and suffer from finite availability [1]. Tissue engineering aims to overcome limited availability by combining more readily available biomaterial scaffolds, most often in the form of decellularized or polymeric matrices, with specific cell populations and bioactive cues to generate readily available tissue grafts [45]. The engineered grafts are then combined with rehabilitation regimens to introduce proper mechanical stimuli to the regenerating environment [13, 38, 39, 47]. The conversion of mechanical stimuli to biochemical and biomechanical signals via a series of mechanotransduction pathways is vital to directing satellite cell activation, muscle fiber hypertrophy, and extracellular matrix structure [16, 23, 34]. In contrast to other targets of tissue engineering, however, a breakthrough drug or bioactive factor has yet to be established that adequately promotes repair and regeneration of severe VML injuries. Therefore, development of a drug-based treatment that can be used in combination with current tissue engineering and regenerative rehabilitation programs to improve regenerative capacity and facilitate functional recovery would be invaluable.

Retinoic acid is vital to numerous developmental processes including skeletogenesis and myogenesis [30, 41]. Selective agonists of nuclear retinoic acid receptor- $\gamma$ (RAR $\gamma$ ) have emerged as a potential potent tool for treatment of skeletal disorders including hereditary multiple osteochondromas and fibrodysplasia ossificans progressiva, the latter being a debilitating condition involving pathological formation of bone in soft tissue sites $[5,18,26,43]$. The mechanisms that provide the foundation for drug efficacy in these conditions including suppression of chondrocyte proliferation and matrix production have further extended to the proposed treatment of primary bone sarcomas, including chondrosarcoma, where these suppressive properties may aid in halting tumor growth and improving efficacy of chemotherapies [42]. Recently, it was observed that RAR $\gamma$ agonists may provide additional benefit to muscle regeneration and reduce the deposition of fibrous and adipose tissues in muscle defects [11]. From this, we hypothesized that the anti-fibrotic and pro-myogenic influences provided by these drugs may aid in altering the pathological environment observed in VML injuries, allowing for increased functional recovery and repair. This study was designed to determine the ability of the selective RAR $\gamma$ agonist, palovarotene (R667), to facilitate recovery of neuromuscular strength in vivo using a clinically relevant model of VML and further highlight its future potential in skeletal muscle repair.

\section{Methods}

\section{Animals}

Research was conducted in compliance with the Animal Welfare Act, the implementing Animal Welfare regulations, and the principles of the Guide for the Care and Use of Laboratory Animals, National Research Council. The facility's Institutional Animal Care and Use Committee approved all research conducted in this study. The facility where this research was conducted is fully accredited by the AAALAC. Male Lewis rats (350$450 \mathrm{~g}$; 11 weeks of age) received pre-surgical administration of buprenorphine-SR $(1.2 \mathrm{mg} / \mathrm{kg}$; s.c., $\sim 30 \mathrm{~min}$ prior) for pain management and were observed postsurgery for signs of distress and abnormal changes in mobility. Animals were euthanized under anesthesia after 4 weeks with a lethal dose of pentobarbital (Fatal Plus) and tissues harvested, Table 1.

\section{VML model}

A full thickness defect was created in the tibialis anterior (TA) muscle as previously reported [20, 21]. Briefly, an incision was made along the lateral aspect of the TA muscle under isoflurane anesthesia. Following blunt dissection of the skin and fascia, a metal plate was inserted between the TA muscle and the underlying extensor digitorum longus (EDL) muscle. The defect was created in the middle third of the TA using a $6 \mathrm{~mm}$ biopsy punch against the plate. The SHAM control group did not receive biopsy. Fascia and skin were closed with absorbable suture and skin clips.

\section{R667 administration}

R667 (palovarotene, CAS410528-02-8) was administered $(300 \mathrm{uL})$ at a concentration of $1 \mathrm{mg} / \mathrm{kg}$ via oral gavage three times per week beginning 1 week after surgery and was continued though the duration of the study. R667 solutions were prepared in dimethyl sulfoxide and mixed with corn oil at a ratio of 30:70 DMSO:corn oil. Vehicle control animals received an R667-absent solution of DMSO and corn oil. Treatment regimen was determined 
Table 1 Gross anatomy and muscle weights

\begin{tabular}{llllll}
\hline Experimental Group & Sample Size & Defect Weight $[\mathrm{mg}]$ & Endpoint Body Weight [g] & TA Weight [mg] & EDL Weight [mg] \\
\hline Sham & 6 & - & $367.2 \pm 4.6$ & $597.9 \pm 18.9$ & $163.1 \pm 1.9$ \\
No Repair & 6 & $71.5 \pm 9.2$ & $372.5 \pm 9.3$ & $566.9 \pm 25.1$ & $163.4 \pm 9.6$ \\
R667 & 6 & $71.1 \pm 10.5$ & $355.8 \pm 5.8$ & $506.6 \pm 42.4$ & $170.4 \pm 11.2$ \\
\hline
\end{tabular}

by scaling the effective dose range of $1.2-4.0 \mathrm{mg} / \mathrm{kg}$ established in previous preclinical mouse models of heterotopic ossification according to FDA issued guidance for industry $[5,11,15,43]$. According to this guidance, $1.2-4.0 \mathrm{mg} / \mathrm{kg}$ palovarotene in mouse is roughly equivalent to $0.1-0.33 \mathrm{mg} / \mathrm{kg}$ in human and $0.5-2.0 \mathrm{mg} /$ $\mathrm{kg}$ in rat.

\section{In vivo neuromuscular strength assessment}

Muscle Function was assessed using a dual-mode lever system (Aurora Scientific, Inc.; Aurora, Canada: Mod. 305b) [7, 21]. Anesthetized animals were placed in a supine position with knee and ankle joints fixed at right angles. The foot was fastened to a pedal coupled to a servomotor-controlled force-displacement transducer and needle electrodes inserted percutaneously around the peroneal nerve. Optimal voltage $(3-9 \mathrm{~V})$ was identified using a series of tetanic contractions (5-10 contractions, $150 \mathrm{~Hz}, 0.1 \mathrm{~ms}$ pulse width, $400 \mathrm{~ms}$ train). The distal tendon of the EDL muscle was severed to isolate force production. Force to torque conversion was performed using a standardized $3 \mathrm{~mm}$ moment arm, followed by normalization to body weight [21].

\section{Histological analysis}

A section of the defect region was collected and fixed in buffered formalin. Specimens were embedded in paraffin, sectioned into 4- $\mu \mathrm{m}$ slices, and stained using standard protocols for Masson's Trichrome. Images were acquired using Axio Scan.Z1 microscope and ZEN imaging software (Carl Zeiss Microscopy; Jena, Germany).

\section{Data analysis}

Data is reported as the mean \pm SEM. Statistical analysis was conducted using GraphPad Prism 7.01 (GraphPad Software Inc., La Jolla, CA). Statistical significance is defined as $p<0.05$ using student $\mathrm{t}$-test or one-way ANOVA with Tukey post-hoc tests for multiple comparisons where appropriate.

\section{Results}

In vivo neuromuscular strength assessment

Functional recovery of the tibialis anterior muscle was assessed in vivo via neural stimulation and determination of peak isometric torque 4 weeks after injury. VML affected limbs with No Repair exhibited maximum isometric torque production of $2.41 \pm 0.32 \mathrm{Nmm} / \mathrm{kg}$ body weight and were significantly reduced compared to SHAM $(p=0.006)$, Fig. 1 A. The $46 \%$ torque deficit in comparison to SHAM illustrates the lack of functional recovery that is a defining characteristic of VML injuries, Fig. 1B. In contrast, treatment with R667 increased torque production to $3.33 \pm 0.39 \mathrm{Nmm} / \mathrm{kg}$ body weight
A)

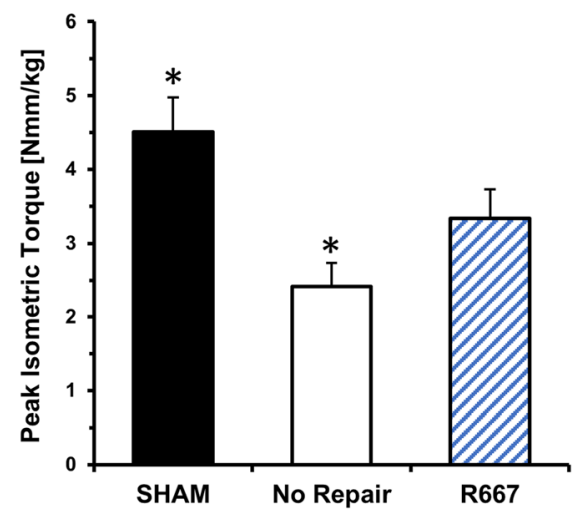

B)

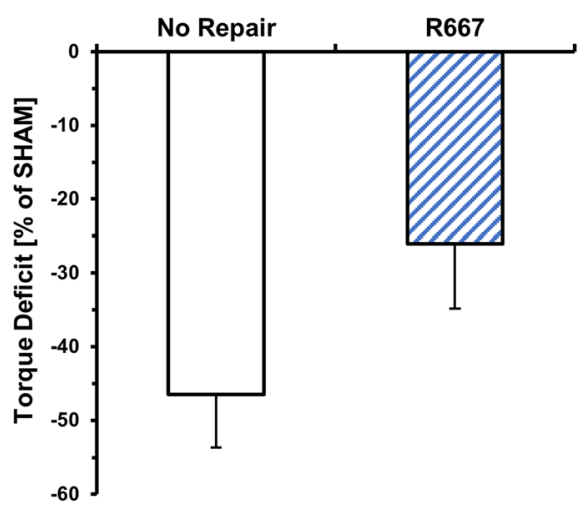

Fig. 1 Oral administration of R667 improves neuromuscular function 4 weeks after volumetric muscle loss. Peak isometric torque normalized to body weight (A) and percent functional deficit relative to SHAM control (B) demonstrate improved functional capacity in the R667 treatment group relative to the No Repair group. *Indicates significant difference between SHAM and No Repair with $p<0.05$. Values are presented as Mean \pm SEM 
and lowered the functional deficit compared to SHAM to $26 \%$. This change in functional deficit for R667 treatment compared to No Repair, however, did not reach statistical significance ( $p=0.099)$, Fig. 1B.

\section{Histological analysis}

Histological staining was performed with Masson's Trichrome to qualitatively assess the level of fibrous tissue deposition into the defect site following injury. As expected, excessive fibrotic scarring was observed following VML injury with the No Repair group consisting of sparsely populated myofibers surrounded by elevated amounts of extracellular matrix deposition, Fig. 2A \& B. In contrast, a qualitative reduction in fibrous scarring was observed at the site of VML in R667 treated animals, Fig. 2C.

\section{Discussion}

The primary aim of this study was to assess the ability of a selective RARy agonist to improve neuromuscular strength in an irrecoverable, rat model of volumetric muscle loss that mimics the persistent functional deficits that present clinically. The results presented here are highly encouraging as they suggest that pharmacological activation of RARs may be a facile and promising method to improve functional recovery and repair of severe skeletal muscle injuries. RARY agonist treatment benefits have previously demonstrated the ability to translate from preclinical models to patient use with phase 3 clinical investigation of fibrodysplasia ossificans progressive (NCT03312634) and phase 2 investigation of multiple osteochondromas (NCT03442985) currently ongoing [37]. A generally favorable safety profile has been observed with treatment strategies similar to those used here, with daily, $5 \mathrm{mg}$ doses being well tolerated for greater than a year, and $20 \mathrm{mg}$ doses routinely administered in response to disease flare ups $[37,44,46]$ Side effects are consistent with general retinoid use with the most reported being mucocutaneous effects of the skin, eye, and gut. Adverse effects on skeletal growth in younger populations are being actively monitored, however, and future risk-benefit assessments will likely be needed in these populations [31, 37]. Of note, the level of functional recovery observed here is similar to that achieved with the tissue engineering-based strategy of minced muscle graft repair [7, 25]. It is hypothesized that combination of RAR $\gamma$ agonists with such cell- and/or scaffold-based systems may be a method to further improve their regenerative capacity and elevate muscle healing beyond current thresholds. Although the precise mechanism by which R667 facilitates restoration of muscle function is not fully elucidated in this study, key pro-myogenic and antifibrotic characteristics of retinoid signaling may provide insight and potential avenues for future exploration.

Retinoids exert transcriptional control through binding of nuclear retinoic acid receptors $(\alpha, \beta$, and $\gamma$ isoforms), followed by complexing with retinoid $X$ receptors $[12,14]$. These complexes bind to retinoid response elements of target genes and interact with a host of repression and activation factors to control
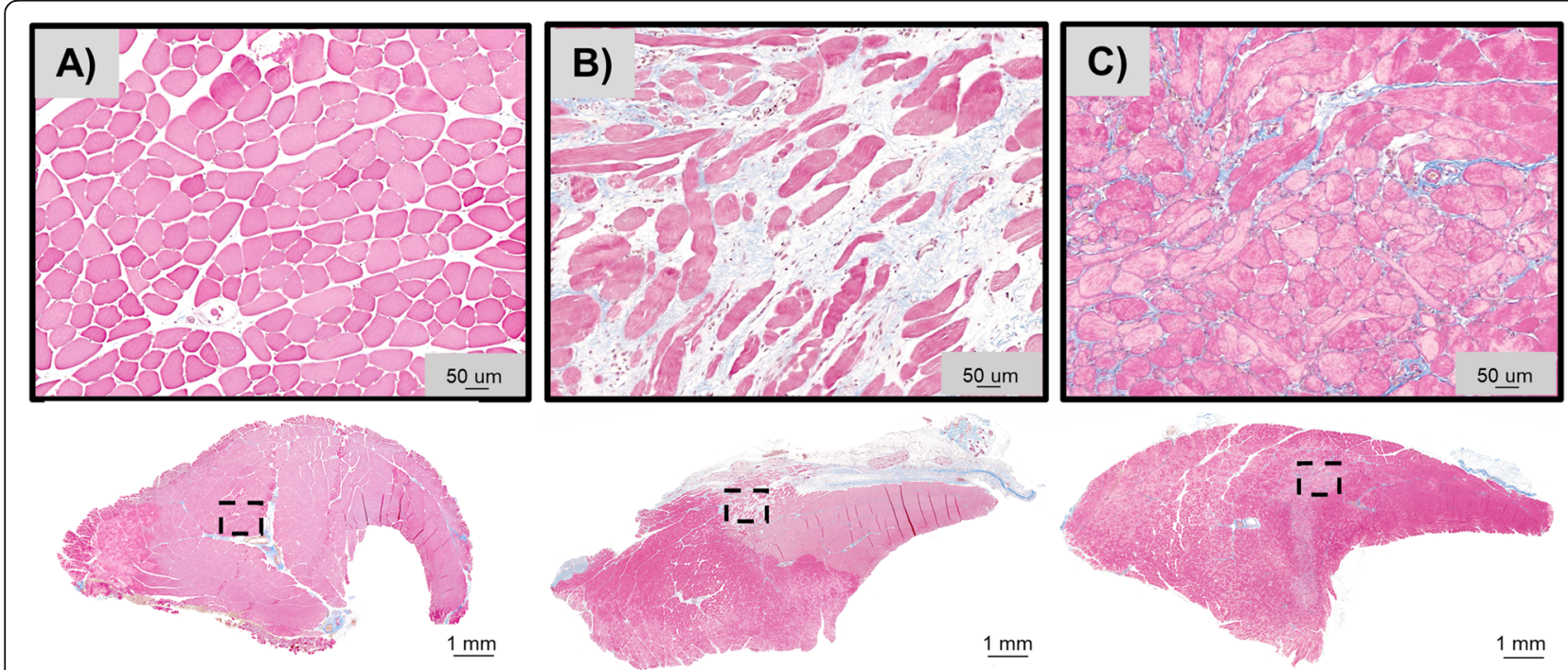

Fig. 2 Histological analysis of tibialis anterior muscle 4 weeks post-injury. Masson's Trichrome staining of SHAM (A), VML injured No Repair (B), and VML injured R667 treated (C) TA muscles. Muscle, fibrous, and adipose tissues are stained red, blue, and white, respectively. Scale bars are $1 \mathrm{~mm}$ for whole mount images and $50 \mu \mathrm{m}$ for regions of interest 
expression patterns. In the absence of retinoid binding, unliganded complexes facilitate transcriptional repression in association with co-repressors such as nuclear receptor co-repressors 1 and 2. Co-repressor activity has been shown to influence muscle mass, oxidative metabolism, and exercise capacity in rodent models [48]. In a study highlighting the importance of $\gamma$ isoform-specific RAR action in skeletal muscle repair, Di Rocco et al. identified dynamic temporal profiles in retinoid signaling following injury and observed that RAR $\gamma$-null mice experienced marked delays in healing [11]. Furthermore, histological characterization of a cautery induced muscle defect revealed that orally administered R667 improved new myofiber formation and reduced the deposition of fibrous and adipose tissue inside the defect. This mitigation of pathological fibrosis has profound implications in muscle healing has been attributed to a reduction in Smad phosphorylation/canonical BMP signaling and increased activity of antichondrogenic Wnt/ $\beta$-catenin pathways [36, 43, 49].

The persistent functional deficits that accompany excessive fibrous tissue deposition in VML injury have been extensively reported $[2,9,22]$. Of note, however, is that a reduction in fibrous tissue deposition alone, without a simultaneous improvement in fiber repair and regeneration, is detrimental to muscle function as it removes a potential conduit for force transmission across the defect [19]. This suggests that improved myofiber regeneration is likely occurring in conjunction with a reduction of fibrous scarring in R667 treated animals. In support, the referenced pathways influenced by retinoid signaling hold significant and complex roles in directing muscle progenitor activity. Wnt/ß-catenin signaling, for example, has been implicated in promotion of satellite cell self-renewal, as well as in actively driving myogenic differentiation $[4,28$, 35, 40]. Furthermore, the modulation of canonical BMP and adipogenic signaling in response to increased retinoid activity could potentially be removing significant barriers to myogenesis that present after injury $[3,17]$.

A noted limitation of the presented work is the absence of quantitative histological assessment of fibrous tissue deposition at the VML site. Future studies will need to evaluate collagen deposition and organization, progenitor cell activity, and myofiber regeneration to provide a better mechanistic understanding of improvements in functional recovery. It should also be noted that this work focused on recovery of muscle function in young rats. Multiple studies have reported on the deleterious effects of age on satellite cell activity and demonstrated the reduced response of aged rats to regenerative therapies for VML repair [6, 27, 29]. Additional study will be needed to identify age related effects on RAR $\gamma$ agonist-induced muscle healing.

\section{Conclusions}

This study serves as an additional data point to suggest that selective RAR $\gamma$ agonists may hold promise in the treatment of severe skeletal muscle injury and warrant further investigation. Here, we demonstrate that oral administration of R667 was able to increase neuromuscular strength in a rat model of volumetric muscle loss. Additional studies are needed to further elucidate RAR $\gamma$-induced cellular responses and characterize synergistic potential with adjunct therapies. Ultimately, this drug may prove a useful tool in the design of novel treatment paradigms to maximize healing of skeletal muscle.

\section{Abbreviations \\ VML: Volumetric muscle loss; RAR: Retinoic acid receptor; R667: Palovarotene; TA: Tibialis anterior; EDL: Extensor digitorum longus}

\section{Acknowledgements}

We thank MAJ Nathan Wienandt, Ms. Shayna Levine, Ms. Monica Farley, Mr. Jerry Garcia, Mr. Pham Phong, Ms. Rebecca Garcia, and Ms. Desiree Romano for their technical assistance. This work was supported in part by the appointment of MW and PC to the Research Participation Program at the U.S. Army Institute of Surgical Research, administered by the Oak Ridge Institute for Science and Education through an interagency agreement between the U.S. Department of Energy and DoD. The views expressed in this article are those of the author(s) and do not reflect the official policy or position of the U.S. Army Medical Department, Department of the Army, DoD, or the U.S. Government.

\section{Authors' contributions}

MW analyzed data and prepared the original manuscript draft. PC, Ml, and JW designed the study and were involved with manuscript review and editing. PC performed experiments and collected data. All authors have read and approved of this manuscript.

\section{Funding}

This work was funded in part by the Congressionally Directed Medical Research Program (CDMRP) (Award: W81XWH-19-2-0044 to MI and JW).

\section{Availability of data and materials}

The datasets used and/or analyzed during the current study are primarily presented in the current manuscript and are available from the

corresponding author on reasonable request.

\section{Declarations}

\section{Ethics approval}

Research was conducted in compliance with the Animal Welfare Act, the implementing Animal Welfare regulations, and the principles of the Guide for the Care and Use of Laboratory Animals, National Research Council. The facility's Institutional Animal Care and Use Committee approved all research conducted in this study. The facility where this research was conducted is fully accredited by the AAALAC.

Consent for publication

Not applicable.

\section{Competing interests}

MI is an inventor of the patent US-9789074-B2 "Composition and method for muscle repair and regeneration" and received licensing fee.

\section{Author details}

'Orthopaedic Trauma Department, United States Army Institute of Surgical Research, 3698 Chambers Pass, Building 3611, JBSA Fort Sam Houston, San Antonio, TX 78234, USA. ${ }^{2}$ Department of Orthopaedics, University of Maryland School of Medicine, 655 W Baltimore St, Baltimore, MD 21201, USA. 
Received: 25 March 2021 Accepted: 30 July 2021

\section{Published online: 12 August 2021}

\section{References}

1. Aguilar CA, Greising SM, Watts A, Goldman SM, Peragallo C, Zook C, Larouche J, Corona BT (2018) Multiscale analysis of a regenerative therapy for treatment of volumetric muscle loss injury. Cell Death Dis 4(1):33. https://doi.org/10.1038/s41420-018-0027-8

2. Aurora A, Roe JL, Corona BT, Walters TJ (2015) An acellular biologic scaffold does not regenerate appreciable de novo muscle tissue in rat models of volumetric muscle loss injury. Biomaterials 67:393-407. https://doi.org/10.1 016/j.biomaterials.2015.07.040

3. Berry DC, DeSantis D, Soltanian H, Croniger CM, Noy N (2012) Retinoic acid upregulates preadipocyte genes to block adipogenesis and suppress dietinduced obesity. Diabetes 61(5):1112-1121. https://doi.org/10.2337/db11-1 620

4. Brack AS, Conboy IM, Conboy MJ, Shen J, Rando TA (2008) A temporal switch from notch to Wnt signaling in muscle stem cells is necessary for normal adult myogenesis. Cell Stem Cell 2(1):50-59. https://doi.org/10.1016/ j.stem.2007.10.006

5. Chakkalakal SA, Uchibe K, Convente MR, Zhang D, Economides AN, Kaplan FS, Pacifici M, Iwamoto M, Shore EM (2016) Palovarotene inhibits heterotopic ossification and maintains limb mobility and growth in mice with the human ACVR1R206H Fibrodysplasia Ossificans Progressiva (FOP) mutation. J Bone Miner Res 31(9):1666-1675. https://doi.org/10.1002/jbmr.2820

6. Chen W, Datzkiw D, Rudnicki MA (2020) Satellite cells in ageing: use it or lose it. Open Biol 10(5):200048. https://doi.org/10.1098/rsob.200048

7. Corona BT, Garg K, Ward CL, McDaniel JS, Walters TJ, Rathbone CR (2013) Autologous minced muscle grafts: a tissue engineering therapy for the volumetric loss of skeletal muscle. Am J Phys Cell Phys 305(7):C761-C775. https://doi.org/10.1152/ajpcell.00189.2013

8. Corona BT, Rivera JC, Owens JG, Wenke JC, Rathbone CR (2015) Volumetric muscle loss leads to permanent disability following extremity trauma. J Rehabil Res Dev 52(7):785-792. https://doi.org/10.1682/JRRD.2014.07.0165

9. Corona BT, Wu X, Ward CL, McDaniel JS, Rathbone CR, Walters TJ (2013) The promotion of a functional fibrosis in skeletal muscle with volumetric muscle loss injury following the transplantation of muscle-ECM. Biomaterials 34(13): 3324-3335. https://doi.org/10.1016/j.biomaterials.2013.01.061

10. Criswell TL, Corona BT, Ward CL, Miller M, Patel M, Wang Z, Christ GJ, Soker $\mathrm{S}$ (2012) Compression-induced muscle injury in rats that mimics compartment syndrome in humans. Am J Pathol 180(2):787-797. https:// doi.org/10.1016/j.ajpath.2011.10.012

11. Di Rocco A, Uchibe K, Larmour C, Berger R, Liu M, Barton ER, Iwamoto M (2015) Selective retinoic acid receptor $\gamma$ agonists promote repair of injured skeletal muscle in mouse. Am J Pathol 185(9):2495-2504. https://doi.org/1 0.1016/j.ajpath.2015.05.007

12. Duester $G$ (2008) Retinoic acid synthesis and signaling during early organogenesis. Cell 134(6):921-931. https://doi.org/10.1016/j.cell.2008.09.002

13. Dziki JL, Giglio RM, Sicari BM, Wang DS, Gandhi RM, Londono R, Dearth CL, Badylak SF (2018) The effect of mechanical loading upon extracellular matrix bioscaffold-mediated skeletal muscle remodeling. Tissue Eng A 24(12):34-46. https://doi.org/10.1089/ten.tea.2017.0011

14. Evans RM, Mangelsdorf DJ (2014) Nuclear receptors, RXR, and the big bang. Cell 157(1):255-266. https://doi.org/10.1016/j.cell.2014.03.012

15. FDA (2005) Estimating the maximum safe starting dose in initial clinical trials for therapeutics in adult healthy volunteers. Food and Drug Administration Center for Drug Evaluation and Research, US Department of Health and Human Services (Available at: https://www.fda.gov/media/723 09/download)

16. Fischer M, Rikeit $P$, Knaus $P$, Coirault C (2016) YAP-mediated mechanotransduction in skeletal muscle. Front Physiol 7:41

17. Friedrichs $M$, Wirsdöerfer F, Flohé SB, Schneider S, Wuelling $M$, Vortkamp A (2011) BMP signaling balances proliferation and differentiation of muscle satellite cell descendants. BMC Cell Biol 12(1):1-17

18. Garcia SA, Tian H, Imamura-Kawasawa Y, Fisher A, Cellini A, Codd C, Herzenberg JE, Abzug JM, Ng V, Iwamoto M, Enomoto-Iwamoto M (2020) Understanding the action of RARy agonists on human osteochondroma explants. Int J Mol Sci 21(8):2686. https://doi.org/10.3390/ijms21082686

19. Garg K, Corona BT, Walters TJ (2014) Losartan administration reduces fibrosis but hinders functional recovery after volumetric muscle loss injury. J Appl Physiol 117(10):1120-1131. https://doi.org/10.1152/japplphysiol.00689.2014
20. Goldman SM, Henderson BE, Corona BT (2017) Evaluation of bone marrow mononuclear cells as an adjunct therapy to minced muscle graft for the treatment of volumetric muscle loss injuries. Stem Cell Res Ther 8(1):142. https://doi.org/10.1186/s13287-017-0589-z

21. Goldman SM, Henderson BE, Walters TJ, Corona BT (2018) Co-delivery of a laminin-111 supplemented hyaluronic acid based hydrogel with minced muscle graft in the treatment of volumetric muscle loss injury. PLoS One 13(1):e0191245. https://doi.org/10.1371/journal.pone.0191245

22. Greising SM, Rivera JC, Goldman SM, Watts A, Aguilar CA, Corona BT (2017) Unwavering pathobiology of volumetric muscle loss injury. Sci Rep 7(1):1-14

23. Greising SM, Warren GL, Southern WM, Nichenko AS, Qualls AE, Corona BT, Call JA (2018) Early rehabilitation for volumetric muscle loss injury augments endogenous regenerative aspects of muscle strength and oxidative capacity. BMC Musculoskelet Disord 19(1):1-11

24. Hardy D, Besnard A, Latil M, Jouvion G, Briand D, Thépenier C, Pascal O, Guguin A, Gayraud-Morel B, Cavaillon J-M, Tajbakhsh S, Rocheteau P, Chretien F (2016) Comparative study of injury models for studying muscle regeneration in mice. PLoS One 11(1):e0147198. https://doi.org/10.1371/ journal.pone.0147198

25. Hurtgen BJ, Ward CL, Leopold Wager CM, Garg K, Goldman SM, Henderson BE, McKinley TO, Greising SM, Wenke JC, Corona BT (2017) Autologous minced muscle grafts improve endogenous fracture healing and muscle strength after musculoskeletal trauma. Phys Rep 5(14):e13362. https://doi. org/10.14814/phy2.13362

26. Inubushi T, Lemire I, Irie F, Yamaguchi Y (2018) Palovarotene inhibits osteochondroma formation in a mouse model of multiple hereditary exostoses. J Bone Miner Res 33(4):658-666. https://doi.org/10.1002/ jbmr.3341

27. Joanisse S, Nederveen JP, Snijders T, McKay BR, Parise G (2017) Skeletal muscle regeneration, repair and remodelling in aging: the importance of muscle stem cells and vascularization. Gerontology 63(1):91-100. https://doi. org/10.1159/000450922

28. Jones AE, Price FD, Le Grand F, Soleimani VD, Dick SA, Megeney LA, Rudnicki MA (2015) Wnt/ $\beta$-catenin controls follistatin signalling to regulate satellite cell myogenic potential. Skelet Muscle 5(1):1-11

29. Kim JT, Kasukonis B, Dunlap G, Perry R, Washington T, Wolchok JC (2020) Regenerative repair of volumetric muscle loss injury is sensitive to age. Tissue Eng A 26(1-2):3-14. https://doi.org/10.1089/ten.tea.2019.0034

30. Koyama E, Golden EB, Kirsch T, Adams SL, Chandraratna RA, Michaille J-J, Pacifici M (1999) Retinoid signaling is required for chondrocyte maturation and endochondral bone formation during limb skeletogenesis. Dev Biol 208(2):375-391. https://doi.org/10.1006/dbio.1999.9207

31. Lees-Shepard JB, Nicholas S-AE, Stoessel SJ, Devarakonda PM, Schneider MJ, Yamamoto M, Goldhamer DJ (2018) Palovarotene reduces heterotopic ossification in juvenile FOP mice but exhibits pronounced skeletal toxicity. Elife 7:e40814. https://doi.org/10.7554/eLife.40814

32. Lefaucheur JP, Sébille A (1995) The cellular events of injured muscle regeneration depend on the nature of the injury. Neuromuscul Disord 5(6): 501-509. https://doi.org/10.1016/0960-8966(95)00012-C

33. Lepper C, Partridge TA, Fan C-M (2011) An absolute requirement for Pax7positive satellite cells in acute injury-induced skeletal muscle regeneration. Development 138(17):3639-3646. https://doi.org/10.1242/dev.067595

34. Olsen LA, Nicoll JX, Fry AC (2019) The skeletal muscle fiber: a mechanically sensitive cell. Eur J Appl Physiol 119(2):333-349. https://doi.org/10.1007/ s00421-018-04061-x

35. Otto A, Schmidt C, Luke G, Allen S, Valasek P, Muntoni F, Lawrence-Watt D, Patel K (2008) Canonical Wnt signalling induces satellite-cell proliferation during adult skeletal muscle regeneration. J Cell Sci 121(17):2939-2950. https://doi.org/10.1242/jcs.026534

36. Pacifici M (2018) Retinoid roles and action in skeletal development and growth provide the rationale for an ongoing heterotopic ossification prevention trial. Bone 109:267-275. https://doi.org/10.1016/j.bone.2017.08.010

37. Pignolo RJ, Al Mukaddam M, Baujat G, Berglund SK, Cheung AM, De Cunto C, Delai P, Di Rocco M, Haga N (2020) Hsiao EC Palovarotene (PVO) for Fihrodysplasia Ossificans Progressiva (FOP): Data from the Phase III MOVE Trial. In: JOURNAL OF BONE AND MINERAL RESEARCH. WILEY 111 RIVER ST, HOBOKEN 07030-5774, NJ USA, pp 16-17

38. Quarta M, Cromie M, Chacon R, Blonigan J, Garcia V, Akimenko I, Hamer M, Paine P, Stok M, Shrager JB, Rando TA (2017) Bioengineered constructs combined with exercise enhance stem cell-mediated treatment of volumetric muscle loss. Nat Commun 8(1):1-17 
39. Rando TA, Ambrosio F (2018) Regenerative rehabilitation: applied biophysics meets stem cell therapeutics. Cell Stem Cell 22(3):306-309. https://doi.org/1 0.1016/j.stem.2018.02.003

40. Rudolf A, Schirwis E, Giordani L, Parisi A, Lepper C, Taketo MM, Le Grand F (2016) $\beta$-Catenin activation in muscle progenitor cells regulates tissue repair. Cell Rep 15(6):1277-1290. https://doi.org/10.1016/j.celrep.2016.04.022

41. Ryan T, Liu J, Chu A, Wang L, Blais A, Skerjanc IS (2012) Retinoic acid enhances skeletal myogenesis in human embryonic stem cells by expanding the premyogenic progenitor population. Stem Cell Rev Rep 8(2): 482-493. https://doi.org/10.1007/s12015-011-9284-0

42. Shield WP III, Cellini A, Tian H, Wilson K, Dan Y, Abzug JM, Garcia S, Moritani N, Alferiev I, Chorny M, Takigawa M, Ng V, Iwamoto M, Enomoto-Iwamoto M (2020) Selective agonists of nuclear retinoic acid receptor gamma inhibit growth of HCS-2/8 chondrosarcoma cells. J Orthop Res 38(5):1045-1051. https://doi.org/10.1002/jor.24555

43. Shimono K, W-e T, Macolino C, Chi AH-T, Didizian JH, Mundy C, Chandraratna RA, Mishina Y, Enomoto-Iwamoto M, Pacifici M, Iwamoto M (2011) Potent inhibition of heterotopic ossification by nuclear retinoic acid receptor- $\gamma$ agonists. Nat Med 17(4):454-460. https://doi.org/10.1038/ nm. 2334

44. Singh S, Kidane J, Wentworth KL, Motamedi D, Morshed S, Schober AE, Hsiao EC (2020) Surgical management of bilateral hip fractures in a patient with fibrodysplasia ossificans progressiva treated with the RAR- $y$ agonist palovarotene: a case report. BMC Musculoskelet Disord 21(1):1-8

45. Smoak MM, Mikos AG (2020) Advances in biomaterials for skeletal muscle engineering and obstacles still to overcome. Materials today bio:100069

46. Stolk J, Stockley RA, Stoel BC, Cooper BG, Piitulainen E, Seersholm N, Chapman KR, Burdon JG, Decramer M, Abboud RT, Mannes GP, Wouters EF, Garrett JE, Barros-Tizon JC, Russi EW, Lomas, DA, MacNee WA, Rames A (2012) Randomised controlled trial for emphysema with a selective agonist of the $\gamma$-type retinoic acid receptor. Eur Respir J 40(2):306-312. https://doi. org/10.1183/09031936.00161911

47. Washington TA, Perry RA Jr, Kim JT, Haynie WS, Greene NP, Wolchok JC (2021) The effect of autologous repair and voluntary wheel running on force recovery in a rat model of volumetric muscle loss. Exp Physiol 106(4): 994-1004. https://doi.org/10.1113/EP089207

48. Yamamoto H, Williams EG, Mouchiroud L, Canto C, Fan W, Downes M, Héligon C, Barish GD, Desvergne B, Evans RM, Schoonjans K, Auwerx J (2011) NCoR1 is a conserved physiological modulator of muscle mass and oxidative function. Cell 147(4):827-839. https://doi.org/10.1016/j.cell.2011.10. 017

49. Yasuhara R, Yuasa T, Williams JA, Byers SW, Shah S, Pacifici M, Iwamoto M, Enomoto-Iwamoto M (2010) Wnt/B-catenin and retinoic acid receptor signaling pathways interact to regulate chondrocyte function and matrix turnover. J Biol Chem 285(1):317-327. https://doi.org/10.1074/jbc.M109.053 926

50. Yin H, Price F, Rudnicki MA (2013) Satellite cells and the muscle stem cell niche. Physiol Rev 93(1):23-67. https://doi.org/10.1152/physrev.00043.2011

\section{Publisher's Note}

Springer Nature remains neutral with regard to jurisdictional claims in published maps and institutional affiliations.

\section{Submit your manuscript to a SpringerOpen ${ }^{\circ}$ journal and benefit from:}

- Convenient online submission

- Rigorous peer review

- Open access: articles freely available online

- High visibility within the field

- Retaining the copyright to your article

Submit your next manuscript at $\boldsymbol{\nabla}$ springeropen.com 